\title{
A FIGURA DA VIRGEM MARIA SOB A ÓTICA DAS CARTAS DOGMÁTICAS E REPRESENTAÇÕES CULTURAIS
}

\section{THE FIGURE OF THE VIRGIN MARY FROM THE POINT OF VIEW OF DOGMATIC LETTERS AND CULTURAL REPRESENTATIONS}

\author{
Sandra de Cássia Araújo Pelegrini ${ }^{1}$ \\ João Paulo P. Rodrigues ${ }^{2}$
}

\begin{abstract}
Resumo: Nos últimos séculos, o papel da Virgem Maria dentro da Igreja Católica passou por uma mudança paulatina substancial. De uma vaga referencia evangélica a um personagem eximiamente familiar e divino de modo equivalente ao seu filho, Nossa Senhora vem recebendo tributos e homenagens ao seu nome na praticamente na mesma proporção que seu filho. Nesse artigo problematizaremos essa transformação da Imaculada, sob dois prismas: documentos e cartas dogmáticas e representações iconográficas e iconológicas da Virgem.
\end{abstract}

Palavras-chaves: História Cultural, Representação, Marianismo, Iconografia.

ABSTRACT: In recent centuries, the role of the Virgin Mary within the Catholic Church has undergone a substantial gradual change. From a vague evangelical reference to an eximely familiar and divine character in a way equivalent to her son, Our Lady has been receiving tributes and tributes to her name in almost the same proportion as her son. In this article we will problematize this transformation of the Immaculate under two prisms: dogmatic documents and letters, feasts in praise and iconographic and iconological representations of the Virgin.

Keywords: Cultural History, Representation, Marianism, Iconography

Podemos considerar que a figura da mãe de Jesus Cristo é tão relevante como a do seu filho no âmbito do catolicismo popular. Este tema tem atraído a atenção de pesquisadores como historiadores, sociólogos e antropólogos que procuram compreender como uma mulher com poucas referencia na bíblia ascendeu substancialmente na hierarquia da devoção de seus fiéis. Para eles, ela é a protetora, a mãe bondosa, a justiceira e a defensora das minorias.

\footnotetext{
${ }^{1} \mathrm{MBP} / \mathrm{UEM}$

${ }^{2} \mathrm{PPH} / \mathrm{UEM}$
} 
A FIGURA DA VIRGEM MARIA SOB A ÓTICA DAS CARTAS DOGMÁTICAS E REPRESENTAÇÕES CULTURAIS

A importância da figura da Virgem Maria nas Bulas Dogmáticas.

As raízes para essa devoção teriam origens milenares, referidas em livros apócrifos, passagens bíblicas e bulas dogmáticas como veremos a seguir. documento biográfico de santos "Legenda Áurea", escrito no século XIII pelo frade Jacopo de Varazze (2003), revela que Maria foi gerada da união de Joaquim, fazendeiro e criador de ovelhas, natural de Nazaré, e Ana, filha de Mathan, um sacerdote que vivia em Belém e tinha outras duas irmãs. Casaram-se prematuramente, o documento menciona que constituíam um casal "justo" e seguidor dos mandamentos do Senhor, no entanto, não conseguiam dar a luz a nenhum filho.

Após 20 anos de amargura e pedidos, Ana engravidou e deu à luz a uma filha, que recebeu o nome de Maria. Ao completar três anos, a menina foi levada ao templo, onde, de acordo com a promessa dos pais, viveria a serviço do divino. A Virgem foi ali educada e só retornou à casa dos pais aos 14 anos para se casar com José.

Segundo a historiadora Edilece Souza Coto (2004), até esse período são pouquíssimos os registros sobre a vida de Maria. Sua biografia torna-se mais completa após o nascimento de Jesus Cristo, nas passagens bíblicas. Ao todo, a Virgem Imaculada é mencionada 19 vezes no Novo Testamento.

Na Carta Encíclica de João Paulo II, "Redemptoris mater" publicada em 25 de março de $1987^{3}$, o Papa destaca algumas aparições da virgem nas escrituras sagradas, com a finalidade de atestar o papel sacro e dogmático de Maria. Entre as passagens, vale destacar: O aparecimento do arcanjo Gabriel no anúncio de que seria ela a mãe do Filho de Deus em Lucas, capítulo 1, versículo 26-56 e na visitação à sua prima Isabel em Lucas, capítulo 1, versículo 39-56.

Outras aparições da Virgem mencionada pelo Pontífice remetem a sua purificação e a apresentação do Menino Jesus no templo em Lucas, capítulo 2, versículo 22-38; na procura pelo menino no templo, quando este debatia com os doutores da lei também em Lucas capítulo 2, versículo 41-50. Na famosa parábola sobre as bodas de Canaã, na Galileia em João, capitulo 2, versículo 1-11. O Papa

\footnotetext{
${ }^{3}$ Para ver mais, consultar: HTTPS://w2.vatican.va/content/john-paul-ii/pt/encyclicals/documents/hf_jpii_enc_25031987_redemptoris-mater.html 
A FIGURA DA VIRGEM MARIA SOB A ÓTICA DAS CARTAS DOGMÁTICAS E REPRESENTAÇÕES CULTURAIS

Sandra de Cássia Araújo Pelegrini

João Paulo P. Rodrigues

reforça que é nessa passagem que a maternidade de Maria é desvelada e ela passa a atuar como mediadora dos homens perante Cristo.

A Virgem é novamente citada na passagem à procura de Cristo enquanto este pregava e o elogio que Ihe faz em Marcos, capítulo 3, versículo 33-35; ao pé da Cruz quando seu filho aponta a Maria como mãe do discípulo e a este como seu primogênito em João, capítulo 19, versículo 26-27 e por último depois da ascensão de Cristo aos céus, onde a Virgem, de acordo com o Evangelho, era uma das mulheres que estavam reunidas com restantes discípulos na passagem de Atos dos Apóstolos. Sobre essa ultima passagem João Paulo atesta:

Há outra passagem do evangelho que confirma essa maternidade na economia salvífica da graça no seu momento culminante, isto é, quando se realiza o sacrificio de cristo na cruz, o seu mistério é pascal. A descrição de São João é concisa "estavam junto à cruz de Jesus sua mãe, a irmã de sua Mãe, Maria, mulher de Clopas, e Maria Madalena'. Jesus, então, vendo a mãe perto do discipulo que amava, disse à mãe: "Mulher eis o teu filho"! Depois disse ao discipulo, eis a tua mãe" e a partir daquele momento o discipulo levou-a para a sua casa. ( JOÃO PAULO, 1987, p.43).

Para o pontífice, desse episódio nasceu um novo vínculo na relação Mãe e Filho, em que a maternidade de Maria em relação aos homens é claramente precisada e estabelecida.

Além da Carta Encíclica publicada em 1987, a Igreja Católica publicou uma série de cartas dogmáticas marianas que atestam três princípios particulares da Virgem: a Virgindade Perpétua, Maternidade Divina e a Imaculada Conceição e Assunção aos céus.

O dogma sobre a Virgindade perpétua enveredou-se nas falas do Bispo Ambrósio de Milão, por volta do ano 391 ou 392, no documento "De Institutione Virginis", que se dedicou em defender a virgindade perpétua de Nossa Senhora. Sobre essa temática, os cristãos acreditam que Maria era pura quando concebeu Jesus, mas apenas a Igreja Católica e os ortodoxos creem que ela ficou eternamente virgem. Alguns setores do catolicismo ligam a ideia da sua pureza na tese do nascimento de Cristo pela profecia de Isaías, presente no capítulo 7 da Biblia Sagrada "Pois saibam que Javé Ihes dará um sinal: A jovem concebeu e Dara à luz um filho, e o chamara pelo nome de Emanuel". 
A FIGURA DA VIRGEM MARIA SOB A ÓTICA DAS CARTAS DOGMÁTICAS E REPRESENTAÇÕES CULTURAIS

Sandra de Cássia Araújo Pelegrini

João Paulo P. Rodrigues

De acordo com Aducci (1998) o segundo dogma, o da Maternidade Divina foi proclamado pela Igreja Católica no Concílio de Éfeso em 431 e posteriormente pautado no Concílio de Calcedônia em 451, esses utilizaram passagens bíblicas para ratificar que Maria seria a Mãe de Deus. O livro bíblico Gálatas capitulo quatro, versículos 4-6 afirma:

"Que ao chegar a plenitude dos tempos, Deus enviou o seu Filho, nascido duma mulher, nascido sob a Lei, a fim de resgatar os que estavam sujeitos à Lei e para que nós recebêssemos a adoção de filhos. E porque vós sois filhos, Deus enviou aos nossos corações o Espírito do seu Filho" (Gál 4, 4-6).

Para Clodovis Boff "os dogmas representam a mariologia "esotérica", aquela que nos faz contemplar a Virgem como que tirando o véu e fazendo ver seu rosto de luz e de beleza". ( BOFF, 1979, p.11). Esses dois primeiros dogmas segue uma ordem de estabelecimento, diferente dos dogmas da "Imaculada Conceição e da Assunção aos Céus". Tanto a Maternidade quanto a Virgindade Perpétua, foram publicados nos primeiros anos do cristianismo, antes do "Grande Cisma" em 1054, portanto pelo papado do Oriente e como uma resposta aos contestadores da Virgem Maria. Além disso, esses Dogmas são aceitos por todas vertentes da lgreja católica, seja ela de rito latino ou bizâncio.

O terceiro dogma refere-se à Imaculada Conceição, publicado em 8 de dezembro de 1854, pelo Papa Pio IX, em que afere que Maria seria a discipula fiel de Cristo, uma vez que ela "via e ouvia tudo o que acontecia com Jesus e meditava em seu coração (Lucas 2,51)". Em sua resolução, o Pio IX pontuava:

Que a doutrina que defende que a beatíssima Virgem Maria foi preservada de toda a mancha do pecado original desde o primeiro instante da sua concepção, por singular graça de privilégio de Deus omnipotente e em atenção aos merecimentos de Jesus Cristo salvador do gênero humano, foi revelada por Deus e que, por isso deve ser admitida com fé firme e constante por todos os fiéis "4.

${ }^{4}$ Disponível em http://www.montfort.org.br/old/index.php?secao $=$ documentos\&subsecao $=$ decretos\&artigo $=20060220 \&$ lang=bra. Acesso no dia 04/07/2011. 
A FIGURA DA VIRGEM MARIA SOB A ÓTICA DAS CARTAS DOGMÁTICAS E REPRESENTAÇÕES CULTURAIS

Sandra de Cássia Araújo Pelegrini

João Paulo P. Rodrigues

De acordo Pedro Carlos Cipollini, esse dogma é por muitas vezes confundido com o da Virgindade Perpétua, "há ainda os que relacionam a Imaculada Conceição de Maria à sua concepção por parte de seus pais, ela teria sido concebida somente segundo a carne, mas não segundo o espírito" (CIPOLLINI, 2017, p.3). Entretanto, para a Igreja católica este dogma, atesta que, por Maria ter sido a serva mais próxima de seu filho, em toda vida a mesma não cometeu nenhum pecado.

O ultimo dogma, da Assunção, foi publicado pelo Papa Pio XII, em 1950, durante a Constituição de "Munificentissimus Deus", ao contrário dos dois primeiros dogmas, esse não se institui a partir de passagens da Bíblia, mas sim de depoimentos de Santos, como São Germano de Constantinopla e São João Damasceno e do próprio Pontífice, na qual destaca que após o seu ciclo de vida, a Virgem teria sido elevada aos céus de corpo e alma:

Pela autoridade de Nosso Senhor Jesus Cristo, dos Santos Apóstolos Pedro e Paulo e em nossa própria autoridade, pronunciamos, declaramos e definimos como sendo um dogma revelado por Deus: que a Imaculada Mãe de Deus, a sempre Virgem Maria, tendo completado o curso de sua vida terrena, foi assumida, corpo e alma, na glória celeste (PIO XII, 1951).

Por meio dessas bulas dogmáticas, Maria paulatinamente passa da condição de Serva do Senhor conforme é mencionada em Lucas, capitulo 1 versículo 38-48, para Mãe de Deus e Mãe da Igreja, entretanto, isso não faz dela a figura principal do catolicismo, uma vez que "os dogmas marianos falam natural e diretamente de Maria: são privilégios, graças muito especiais que ela recebeu de Deus. Mas não só isso; eles falam também de Cristo: a Virgem recebeu essas graças, em função de Cristo" (BOFF, 1979, p.11).

Aliada as bulas dogmaticas, Maria se empoderou fundamentalmente nas transformações iconológicas e iconográficas. O historiador Saez (2008) ressalta que as primeiras imagens da Virgem fazem claras referências aos modelos sírios:

Talvez o primeiro episódio digno de destaque na história dessa iconografia (de acordo com a obra clássica de Emile Male) seja a vitória dos modelos figurativos sírios. Até hoje, essa figura envolta no maphorion. Que cobre a cabeça e oculta os cabelos continua sendo a representação mais comum da virgem, derrotando os primeiros 


\section{HISTÓRIA}

A FIGURA DA VIRGEM MARIA SOB A ÓTICA DAS CARTAS DOGMÁTICAS E REPRESENTAÇÕES CULTURAIS

Sandra de Cássia Araújo Pelegrini

João Paulo P. Rodrigues

ensaios iconográficos gregos, que a representavam com as roupas e o penteado das damas nobres do Império (SAEZ, 2008, p. 208).

No início do segundo milênio, a iconografia mariana se desenvolve a partir do modelo da Theotokos bizantina, o pesquisador considera que a figura da Virgem nesse momento aparece sentada num trono ou servindo de trono para Jesus Cristo. Paulatinamente essa Nossa Senhora hierática e distante de qualquer humanidade, foi sendo substituída por figuras mais flexíveis que apresentavam não mais um deus sentado num trono carnal e sim uma criança no colo da mãe (SAEZ, 2008, p. 208). Paralelamente, essa mudança substancial, a imagem da Virgem passou a agregar em sua face emoções (a dor e o suplicio) como forma de representar a sua humanidade.

Saez (2008) afirma que a figura Maria deveria ser ao mesmo tempo divina e humana, divina porque era uma mãe excepcional para época afinal gerava em seu ventre um ser sagrado e simultaneamente humano. Assim a maneira mais comum de representar essa dignidade consistia em lhe atribuir os atributos da realeza (SAEZ, 2008, p. 207). Por isso as menções e títulos como Rainha, Rainha Mãe e Rainha da Paz.

Sobre o assunto a antropóloga Reesink assinala:

A imagem de Nossa Senhora, na fala de Paulo, é também símbolo distintivo, marca de um espaço católico - onde se encontra o fiel -, que se diferencia de outros espaços, pois ainda é sacro. A sacralização, [...] está diretamente relacionada com a proteção (e também com essa distinção), pois a proteção se dá em razão da sacralização do espaço e da pessoa. Isso induz a pensar que o carro é protegido e protege as pessoas, porque a imagem da Santa, no vidro, o torna sacralizado, intocável. A ideia é que a própria imagem carrega um poder sacralizante que livra e protege do profano, ao sagrar o espaço que toca. O profano, nessa concepção, é o mal e todas as desgraças que ele acarreta. Assim, com uma imagem o sagrado entra nesse lócus profano e o santifica separando-o. (REESINK, 2005, p. 274).

Couto (2004) atesta que na iconografia a figura de Maria se apresenta em distintas posições do corpo e cortes das vestes, carregando ou não o descendente de Deus nos braços, envolto de objetos variados. A historiadora afirma que normalmente a Virgem utiliza uma túnica branca, um manto azul, e traz na cabeça a coroa real. Nas imagens presentes nas igrejas é habitual se encontrar a Rainha sobre o planeta terra 


\section{HISTÓRIA}

A FIGURA DA VIRGEM MARIA SOB A ÓTICA DAS CARTAS DOGMÁTICAS E REPRESENTAÇÕES CULTURAIS

Sandra de Cássia Araújo Pelegrini

João Paulo P. Rodrigues

amarfanhando uma serpente, ícone do pecado original e da visão dualista do sexo feminino: mãe bondosa e acolhedora e, ao mesmo tempo, maligna e tentadora.

Para Couto (2004) nas imagens dos cultos populares, o animal está vivo, circundando a terra ou enrolada no corpo da estátua. Nesse caso, a cobra tem outro significado: simboliza a procriação, a fertilidade presente nos antigos cultos agrários. Sob os seus pés podem aparecer uma lua em fase crescente e cabeças de anjos, na ilustração abaixo observar um exemplo dessa figura, representada na imagem de Nossa Senhora da Conceição:

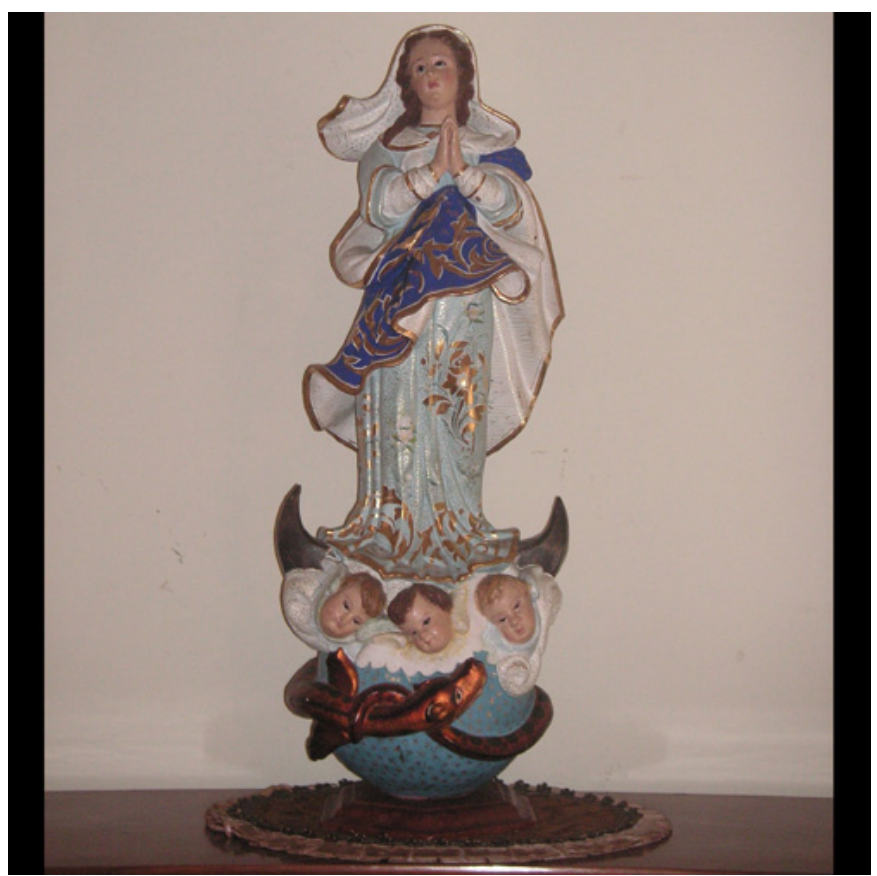

Figura 1: Nossa Senhora da Conceição. Disponível em http://www.serralvesantiguidades.com. Acesso no dia 25/02/2017.

Esta imagem trata-se de um monumento português, do século XIX. A escultura está representada de pé com as mãos postas em oração. O rosto possui uma expressão graciosa e dócil. Ostenta uma túnica drapeada até aos pés com manto em movimento, firmada sobre uma lua crescente e três cabeças de anjo. Abaixo constatamos um globo terrestre envolvido por uma cobra.

Assim, as representações desses temas fascinantes apresentam aspectos que são peculiares a esse meio. Roger Chartier (1988) embasado na obra de Michael de Certeau (1982), em "A História Cultural: entre práticas e representações” escritas 
A FIGURA DA VIRGEM MARIA SOB A ÓTICA DAS CARTAS DOGMÁTICAS E REPRESENTAÇÕES CULTURAIS

Sandra de Cássia Araújo Pelegrini

João Paulo P. Rodrigues

entre os anos de 1982 a 1986, constitui-se como uma resposta à insatisfação sentida frente à história cultural das décadas de 1960 e 1970, compreendidas como história das mentalidades e história quantitativa. Chartier esclarece que deveria ser extinta a visão de que a história quantitativa reconstrói a realidade tal como ela é ${ }^{5}$.

A contagem das palavras, dos títulos, dos motivos, das representações coletivas, são insignificantes e incapazes de reconstruir os significados complexos, conflitos e contradições que existem no pensamento coletivo. Ao captar os pensamentos e as condutas nas suas expressões repetitivas, essa perspectiva falha, pois deixa passar despercebido o essencial, que são os contrastes existentes entre os indivíduos.

Para o historiador francês, o conceito de representação estaria relacionado como a maneira como o indivíduo ou uma comunidade podem se apropriar de uma determinada prática cultural e dessa prática emergirem novas práticas culturais. Por conseguinte, a representação é vista como o "relacionamento de uma imagem presente e de um objeto ausente" (Chartier, 2002, p. 21).

De acordo com Chartier:

Em determinada época, o cruzamento de diferentes suportes (linguísticos, conceituais, afetivos) comanda modos de pensar e de sentir [...], por exemplo, sobre os limites entre o possível e o impossível ou sobre as fronteiras entre o natural e o sobrenatural. (Chartier, 2002, p. 31).

Para Chartier (2002), as representações coletivas podem ser consideradas um conjunto de bases responsáveis pela sustentação das práticas culturais que edificam o próprio mundo social: "Mesmo as representações coletivas mais elevadas não têm existência, não são realmente tais senão na medida em que comandam atos" (Chartier, 2002, p. 11).

O historiador francês elucida que a maneira como o indivíduo se apropria de uma forma cultural é mais importante que a distribuição estatística dessa forma. É importante identificar a maneira como nas práticas, nas representações ou nas produções encontram-se as diferentes formas culturais. Charter pontua a relevância

\footnotetext{
${ }^{5}$ Cumpre lembrar, que Nobert Elias (1994) em "O Processo Civilizador Uma história dos costumes" elucida que alguns hábitos e costumes são alterados a partir do momento que as sociedades tornamse mais flexíveis.
} 
A FIGURA DA VIRGEM MARIA SOB A ÓTICA DAS CARTAS DOGMÁTICAS E REPRESENTAÇÕES CULTURAIS

Sandra de Cássia Araújo Pelegrini

João Paulo P. Rodrigues

dos estudos de Certeau ao reformular o conceito de prática, ora vista como parte de um comportamento:

As práticas que analisou eram as das pessoas comuns, práticas cotidianas, com fazer compras, caminhar pela vizinhança, arrumar a mobília ou ver televisão. Uma razão para ele se referir às "práticas" e não ao "comportamento", era fazer com que seus leitores levassem as pessoas sobre as quais ele escrevia tão a sério quanto elas mereciam (CHARTIER, 1998, p.103).

Assim, Chartier caminha contra a oposição entre criação e consumo, ou passividade contra invenção. Afirmando que o próprio consumo cultural, não no sentido de fabricar um objeto, mas de produzir representações, distintas a quem o próprio produtor inventou nesse caso as imagens apropriadas e representadas conforme a realidade ou necessidade social de uma dada comunidade.

De acordo com Couto (2004), dogma da Imaculada Conceição provavelmente teria sido o primeiro a ser difundido no Brasil pelos portugueses como forma de louvor e tributo. Tomé de Souza teria trazido uma imagem da santa e, ao fundar a cidade do Salvador em 1549, participou ativamente da construção da primeira capela na Cidade Baixa, denominando a Igreja de Nossa Senhora da Conceição da Praia. Nesse espaço os marinheiros e comerciantes locais faziam suas orações em louvor à padroeira do Reino.

Entre os séculos XVI e XVIII, no que diz a respeito da à organização desses momentos de culto coletivo, a Igreja e o Estado apresentam-se como cúmplices em tais praticas. Tal parceria se insere no contexto quando a Igreja Católica e o Estado português oficializaram a política de união dos poderes seculares e imateriais por meio do sistema de Padroado.

Segundo Maura Regina Petruski (2008), a partir de tal "união criou-se uma legislação" estabelecendo as práticas religiosas coletivas como obrigatórias para todos os moradores da colônia, impostas por lei, e os súditos da Coroa não podiam delas se furtar.

Representações da Virgem Maria: do Rocio a das Nuvens. 
A FIGURA DA VIRGEM MARIA SOB A ÓTICA DAS CARTAS DOGMÁTICAS E REPRESENTAÇÕES CULTURAIS

Sandra de Cássia Araújo Pelegrini

João Paulo P. Rodrigues

Na região que mais tarde seria o Estado do Paraná, também encontramos uma normatização que regia essa perspectiva. Os Provimentos estabelecidos pelo Ouvidor Geral de São Paulo, Raphael Pires Pardinho, datados de 20 de janeiro de 1721, nos itens números 5 e 6 estabeleciam aos habitantes da Vila de Curitiba:

$5^{\circ}$. Prove-o que os Juízes e oficiais da câmera assistiram em corpo de câmera a procissão de Corpus Christi, que o Reverendo Vigário e fregueses devem fazer conforme o Sagrado concílio Tridentino. E todas as pessoas que costumam andar na Governança desta Vila serão obrigadas a vir assistir a dita procissão (SANTOS, 1997, p.31).

Diante de seu caráter oficial e impositivo, a participação da população nas manifestações públicas de fé era relevante, tanto da população geral quanto do comando político. Assim, as festividades religiosas estavam presentes em vias, bairros e cidades brasileiras, tendo sua organização e concepção realizada pelos representantes da Igreja ou pelos leigos e fiéis.

Existem relatos de imagens da Virgem Maria que teriam sido encontradas em grutas, montanhas, florestas, arbustos, rios, rochas e, segundo a crendice popular, teriam pedidos pela construção de um templo em sua intenção. "O desrespeito à sua ordem pode ocasionar alguma desgraça, como uma peste. A Senhora é sempre teimosa e não aceita que sua igreja seja construída longe do local onde ela foi encontrada" (COUTO, 2004, p. 98). É o caso da história de Nossa Senhora do Rocio, padroeira do Paraná.

A história da Virgem do Rocio pode ser considerada um exemplo de como as imagens de Maria é apropriado e ganham um novo sentido na cultura popular. Segunda Edésia Aducci (1998) Rocio é uma aldeia situada ao oeste da província de Andaluzia, cerca de $20 \mathrm{~km}$ da antiga cidade de Almonte, é neste espaço que teria acontecido à milagrosa aparição de Nossa Senhora. Aducci (1998) lembra que a imagem teria sido encontrada por um caçador, no tronco de uma árvore, onde provavelmente teria sido escondida pelos moradores de Almonte durante a dominação dos sarracenos.

O caçador resolveu levar a imagem para Almonte, quando parou para descansar percebeu que a santa teria desaparecido. Confuso, voltou para o local onde tinha encontrado a estátua e se deparou com a mesma. Assombrado com o ocorrido 
A FIGURA DA VIRGEM MARIA SOB A ÓTICA DAS CARTAS DOGMÁTICAS E REPRESENTAÇÕES CULTURAIS

Sandra de Cássia Araújo Pelegrini

João Paulo P. Rodrigues

teria se sentido humilhado e sem coragem de carregá-la novamente, teria seguido para Almonte, a fim de comunicar o milagre.

A notícia se espalhou rapidamente por toda Andaluzia. Num breve espaço de tempo construíram um altar e posteriormente um santuário para a santa Foi denominada de Nossa Senhora de Rocinas, pois assim se chamava a então atual aldeia de Rocio.

Os habitantes de Almonte acreditam que foi a Virgem do Rocio que os livrou de epidemias em 1637, de uma grande seca em 1730, de epidemias em 1738 e 1744, da invasão de Napoleão em 1810 e da "fúria dos vermelhos" de 1936.

Atentamos para a aparição da mesma em território paranaense, segundo Sirlene Machado (1998) existem duas versões sobre o aparecimento da Virgem do Rocio na cidade de Paranaguá.

A primeira refere-se ao local onde hoje se encontra o Santuário do Rocio, na cidade de Paranaguá no Paraná, alguns pescadores dedicavam-se aos seus afazeres. Certo dia, Pai Berê, pertencente a este grupo lutava obstinadamente a rede de pesca lançada ao mar, não obtendo êxito algum para alimentar a sua prole. Desconfortado, pediu aos céus que não o desamparasse, lançou novamente as redes e ao puxá-la encontrou uma pequena imagem da Virgem Maria.

Berê passou a rezar o terço com seus vizinhos todas as noites, Machado (1998) conta que por diversas vezes o negro quis levar a imagem para a Igreja Matriz, mas esta teria sempre voltado à noite ao seu antigo lugar, onde surgira e hoje se encontra o Santuário do Rocio. Como em Almonte, a fé paranaguara à virgem aumentou após o ano de 1686, quando a pequena vila foi assolada pela Peste da Bicha e assim a Santa teria sido invocada para que livrasse desta lamúria o vilarejo.

A segunda versão, conta o aparecimento de Maria em uma touceira de rosas, no local onde se encontra o seu santuário. Segundo a memorialista, em novembro essas rosas desabrocham em cachos coloridos, que se despetalam ao vento. Numa noite alguns pescadores teriam visto por volta da meia noite, um grande clarão que saia das águas da baia de Paranaguá e como uma estrela repousava na moita dessas rosas. Curiosos e julgando tratar-se de algum tesouro escondido, foram ao local na manhã seguinte e com surpresa encontraram a imagem de Nossa Senhora ainda coberta pelo orvalho da madrugada. 
A FIGURA DA VIRGEM MARIA SOB A ÓTICA DAS CARTAS DOGMÁTICAS E REPRESENTAÇÕES CULTURAIS

Sandra de Cássia Araújo Pelegrini

João Paulo P. Rodrigues

Ao observamos as passagens que narram a história sobre a Virgem do Rocio, percebemos a existência de determinados elementos que teriam sido apropriados conforme o contexto histórico local e revelam as necessidades de algum grupo em constante suplicio. Atentamos para a maneira que a virgem é encontrada (sempre envolto de alguma adversidade ou algum fenômeno considerado fantástico) ou as lamentações enfrentadas pela santa sempre padecendo a favor do seu povo (no caso as epidemias e pestes que assolavam a região).

Como na parábola bíblica no evangelho de João, capitulo 21 onde Jesus teria se manifestado milagrosamente no mar de Tiberíades, nas passagens do Rocio a Virgem se revela ou na Baia de Paranaguá ou na aldeia em Almonte, na qual a partir desse fenômeno constrói-se o espaço sacralizado onde Maria passa a atuar como Mãe e protetora desses fiéis.

Como podemos constatar, algumas nomeações recebem determinados termos em função de um fenômeno ou acontecimento "fantástico" que permeia a aparição da Virgem que teria estabelecido contato com os devotos tendo em vista "alertar seus filhos" ou livrá-los do pecado por meio de graças ou milagres. Dentro dos títulos cabíveis a Maria pode mencionar alguns com dominações bem particulares e pontuadas por Aducci (1998):

\section{Nossa Senhora da Gota de Ouro}

Esta denominação prove de um riacho chamado "Gota de Ouro" cuja nascente se encontra em Launay, cantão de Beaumont-le-Roger na França. A Virgem é invocada todo dia 8 de setembro.

\section{Nossa Senhora das Treze Pedras}

Em Villefranche-de-Rouergue na França, um carroceiro dado em apuro por sua carroça estar atolada implorou o auxílio de Nossa Senhora, que teria aparecido acompanhada dos doze apóstolos, pousando seus pés, com precaução, nas treze pedras que tinham sido colocadas nesse lugar por ocasião das inundações, para ajudar os pedestres a atravessar a difícil passagem. De acordo com Aducci (1998) o bispo, informado do milagre, benzeu as treze pedras e construiu ali o santuário em louvor a Virgem. 
A FIGURA DA VIRGEM MARIA SOB A ÓTICA DAS CARTAS DOGMÁTICAS E REPRESENTAÇÕES CULTURAIS

Sandra de Cássia Araújo Pelegrini

João Paulo P. Rodrigues

\section{Nossa senhora do Brasil}

Em 1829 foi enviada de Nápoles para os padres brasileiros uma imagem de Nossa Senhora que conservam na igreja de Santo Efren. Aducci (1998) conta que no dia 22 de fevereiro de 1840, um incêndio teria destruído toda igreja em que abrigava à santa, no entanto apenas a imagem não teria padecido sobre as chamas. Fundouse assim a devoção a Nossa Senhora do Brasil, na cidade de São Paulo.

\section{Nossa senhora da Árvore}

Na cidade de Chanonat na França, em 1703, teria sido encontrada uma imagem numa cavidade de uma árvore, desde então a imagem passou a ganhar contornos de milagrosa. A peregrinação a este espaço se da no ultimo domingo de setembro.

\section{Nossa Senhora das Nuvens}

No fim de 1696, na cidade de Quito, Equador, encontrava-se gravemente enfermo o bispo de Quito, dom Sancho de Andrade e Figuerôa. Os médicos declararam-se impotentes para curar o mal e aconselharam ao paciente que recebesse os santos sacramentos. Tristes pela doença do Bispo, os habitantes de Quito teriam combinado de fazer uma manifestação de violência ao céu tomando Nossa Senhora por intercessora.

Em 30 de dezembro de 1696, tanto por causa das preces a favor de seu bispo como por ser domingo, saiu da referida igreja a procissão em louvor a Virgem do Rosário Chegando cortejo ao adro da igreja de São Francisco, um sacerdote teria levantado a voz, exclamando: "A Virgem! A Virgem!". Aos gritos do sacerdote todos levantam os olhos, dirigindo-os para o ponto do céu que ele assinalava com o dedo. Eram 5 horas da tarde. Via-se uma gigantesca imagem da Santíssima Virgem, formada como que de uma nuvem branquíssima e resplandecente, suspensa entre o céu e a terra. Aducci (1998) conta que se viam distintamente os traços do rosto, inclinado a Jesus Cristo que o tinha no braço esquerdo, e no direito, um ramo de açucenas. 
A FIGURA DA VIRGEM MARIA SOB A ÓTICA DAS CARTAS DOGMÁTICAS E REPRESENTAÇÕES CULTURAIS

Sandra de Cássia Araújo Pelegrini

João Paulo P. Rodrigues

A aparição se manteve no ar por alguns segundos e o prodígio da Nuvem foi confirmado pela cura inesperada e rápida de S. Exa. Dom Sancho que teria iniciada no momento da aparição. Em prova de gratidão, dom Sancho não só autorizou o culto de Nossa Senhora da Nuvem para seus diocesanos, mas também erigiu na catedral de Quito um altar especial em sua honra.

\section{Apontamentos}

Através das bulas dogmáticas e das representações, Maria passou de uma breve referencia evangélica assumindo status de protagonista no âmbito do catolicismo popular. A crença nesses dogmas, como por exemplo, o da "Virgindade de Maria garante a fé na divindade de Jesus (enquanto a Maternidade garante a fé na humanidade de Cristo)" (BOFF, 1979, p.24). Ela é mãe, intercessora e protetora.

No estudo de caso, observamos que a história da Virgem do Rocio se assemelha a tantas outras permeadas no território nacional. No Brasil a Virgem Maria possui diversas representações, que segundo Aducci (1998) realiza função importante na Igreja Católica: a de universalizar a devoção a Nossa Senhora ligando-a nas causas articuladas no templo cristão, que seriam os mesmos que os do seu filho Jesus Cristo.

Como foi pontuado, o culto mariano não é homogeneo, a Mãe de Jesus possui diversas represetanções e varios significados construidos e apropriados conforme o espaço causa ou circunstancia. Enquanto para a Igreja Maria é a Nossa Senhora, para o povo ela é singelamente a Senhora, a Mãe. De índole dogmática, para os fiéis a Virgem é considerada uma criatura privilegiada pelas prerrogativas que Deus lhe concedeu. Maria é admirada pela bondade, amabilidade, modéstia, pela santidade que irradiava de todo seu ser, e pela beleza física, pois a Rainha é considerada depois de seu filho a mais perfeita das criaturas.

Nesse âmbito, segundo Couto (2004) a sua figura a torna ainda mais acessível e humana quando é representada no contato direto com camponeses, pescadores, enfermos, crianças, fiéis e pecadores. São por esses atributos que o culto popular mariano vem se permeando em séculos, manifestados nas formas de devoção inspirada por sentimentos como a confiança na bondade, na misericórdia, na sabedoria e no poder "miraculoso" da Matriarca Divina. Entretanto, "as proporções 
A FIGURA DA VIRGEM MARIA SOB A ÓTICA DAS CARTAS DOGMÁTICAS E REPRESENTAÇÕES CULTURAIS

Sandra de Cássia Araújo Pelegrini

João Paulo P. Rodrigues

que tomaram o culto e as várias atribuições a Maria ao longo da história parecem, de alguma forma, extrapolar os estreitos limites que a encarceram nos textos que a retratam e que a reduzida referência evangélica lhe confere" (SILVA, 2010, p.109). Uma vez que o cristianismo ainda em sua gênese proclamava o "Principio de Trindade" em um tripé masculino: Pai, filho e Espirito Santo. Panorama que foi paulatinamente mudado com a primeira carta dogmática em 391 nas falas do Bispo Ambrósio de Milão, sobre a Virgindade perpétua.

\section{Referências Bibliográficas.}

ADUCCI, Edésia. Maria e seus títulos gloriosos. São Paulo. Ed Loiola. 1998.

AQUINO, Mauricio de. História e Devoção. A construção Social do culto a Nossa Senhora Aparecida do vagão queimado de Ourinhos (1954-2004). Bauru. EDUSC. 2011.

Bíblia Sagrada Edição Pastoral. Editora Paulus. 1990

BOFF, L. O rosto materno de Deus. Petrópolis: Vozes, 1979;

CERTEAU, M A invenção do cotidiano: 1, Artes de fazer. Petrópolis: Vozes, 1994.

CHARTIER, R. História cultural: entre práticas e representações. Rio de Janeiro: Bertrand Brasil, 1988.

CHARTIER, Roger. À Beira da falésia: a história entre incertezas e inquietudes. Trad. Patrícia Chittoni Ramos. Porto Alegre: Ed. Universidade/UFRGS, 2002.

CIPOLLINI. Pedro Carlos. O dogma da Imaculada Conceição. Edições CNBB. Santo André.2017

ELIAS, N. O processo civilizador: Uma história dos costumes. Rio de Janeiro: Jorge Zahar. Ed., 1994, v I.

COUTO, Edilece Souza. Tempo de festas: homenagens a Santa Bárbara, N. S. da Conceição e Sant'Ana em Salvador (1860 - 1940). (dissertação) UNESP. 2004. Assis. São Paulo.

DE VARAZZE, J. (2003). Legenda áurea: vida de santos. São Paulo, Companhia das Letras. MACHADO. Nossa Senhora do Rocio, padroeira do Paraná. Curitiba. Governo do estado do Paraná. 1998.

PETRUSKI, R. Maura. Julho Chegou... E A Festa Também: Sant'ana E Suas Comemorações Na Cidade De Ponta Grossa (1930-1961). Tese \(Doutorado em História) - Universidade Federal do Paraná, Curitiba, 2008.

POPE PIUS XII: "Munificentissimus Deus - Defining the Dogma of the Assumption". Vatican, November 1, 1950. 
A FIGURA DA VIRGEM MARIA SOB A ÓTICA DAS CARTAS DOGMÁTICAS E REPRESENTAÇÕES CULTURAIS

Sandra de Cássia Araújo Pelegrini

João Paulo P. Rodrigues

REESINK, Misia Lins, PARA UMA ANTROPOLOGIA DO MILAGRE: Nossa Senhora, seus devotos e o regime Militar. Caderno CRH. Salvador v.18, n.44. p. 267-280. 2005.

SAEZ, Oscar Calavia. Ídolos, mitos, legendas. Sobre a interpretação da iconografia católica. In: MANOEL, Ivan Manoel; ANDRADE, Solange Ramos de (Orgs). Identidades religiosas. Franca: UNESP-FHDSS; Civitas Editora, 2008. p. 203-227

SANTOS, Antônio César de Almeida. Provimentos do ouvidor Pardinho para Curitiba e Paranaguá (1721) in. TOMAZI, Nelson Dacio. "Norte do Paraná" História e Fantasmagorias. Tese (Doutorado em História) - Universidade Federal do Paraná, Curitiba, 1997.

SILVA, B. S. . Imagens e representações de Nossa Senhora no periódico O Mensageiro. Encontro Nacional de Pesquisadores de Periódicos Literários, 4., 2010, Feira de Santana. Anais. Feira de Santana: Uefs, 2013. 